\title{
Risk of Acute Diarrheal Disease in Peri-Urban Areas of Chennai, India
}

\section{Lavanya Vaithyanathan*}

Department of Civil Engineering, Jerusalem College of Engineering, Water Resource Anna University, India

"Corresponding author: Lavanya Vaithyanathan, Jerusalem College of Engineering, Water Resource Anna University, Chennai, India.Tel: +919976229633; Email: lavsdev@gmail.com

Citation: Vaithyanathan L (2017) Risk of Acute Diarrheal Disease in Peri-Urban areas of Chennai, India Countries. J Community Med Public Health: CMPH-105. DOI: 10.29011/CMPH-105/100005

Received Date: 17 July, 2017; Accepted Date: 04 August, 2017; Published Date: 11 August, 2017

\begin{abstract}
Acute Diarrheal Disease is environmental mediated health risk, so it is important to understand the environmental pathways through which the risk can move. This study considers environmental determinants which are closely related to social determinants, because environmental set up of a household decides the socioeconomic condition. Microbiological aspects of drinking water lie under environmental determinants, sanitation and health aspects lie under social determinants. Hence, the focus must be on identifying the risk pathways between the potential source of contamination of the well and its implication on health. This paper aims to assess the risk of ADD due to unprotected water supply and inadequate sanitation in a Peri-urban area of Chennai. 290 individuals were administered for interview, and water samples were collected from the entire interviewed household and analyzed for indicator organism E.coli. This research reveals a greater complex relationship exist between socioeconomic condition and Diarrheal prevalence.
\end{abstract}

Keywords: ADD; E.coli; Sanitation; Peri-urban

\section{Introduction}

Diarrhoea is defined as the passage of three or more loose or liquid stools per day (or more frequent passage than is normal for the individual). Frequent passing of formed stools is not diarrhea, nor is the passing of loose, "Pasty" stools by breastfed babies. The WHO reported in the updated fact sheet that in general low-income countries, children under three years old experience on average three episodes of diarrhea every year. Each episode deprives the child of the nutrition necessary for growth [1]. Diarrheal is the symptom of infection in the intestine caused by a host of bacterial viral and parasitic organism [2]. The health risk due to ADD depends likely on the socio-economic condition of a household. Socio economic stratification is relevant in several aspects of public health research. Variations in normal preventive health behavior tend to be more highly correlated with income, education, and occupation than with other attributes [3]. Hygiene measures or behaviors substantially reduce the infection which was proved by several studies published from 1980-2001[4]. As such, a linkage may exist between the, Socio-economic conditions, E. coli contamination in drinking water and ADD prevalence in suburban communities which is exposed to the dangers of development pressure. The Figure1shows hypothetical relationships feasible.

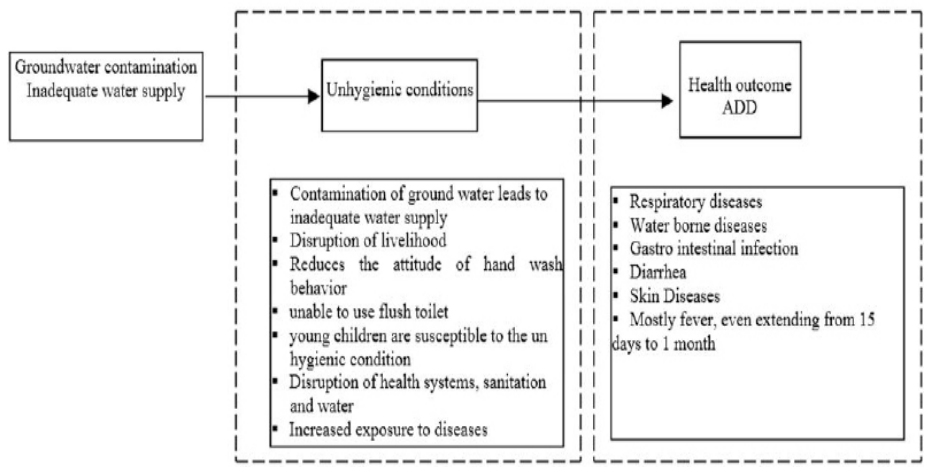

Figure 1: Pathways of Health Impact Due to Water Stress and Unhygienic Conditions.

\section{Materials and Methods}

The Pallikaranai Panchayat union is chosen as the study area. It is one of the fast-developing suburban in south Chennai. The Panchayat union adjoins the Pallikaranai marsh and the Perungudi solid waste dumpsite. The area is a mixture of new set- 
Citation: Vaithyanathan L (2017) Risk of Acute Diarrheal Disease in Peri-Urban areas of Chennai, India Countries. J Community Med Public Health: CMPH-105.

tlers, middle class and slum development squatters with a cross section of people with varied economic class.

Sample size of 290 households from the study area was selected based on stratified randomly sampling. As per 2001 census, there are 15 wards in Pallikaranai. Each ward has household ranging from 75-450, a list of streets in all the wards and their household was collected from Panchayat office. From the 15 wards 20 household having children in the age group 0-5 and 6-12 years were selected in two phases. The same questionnaire was administered for the two phases orally to the respondents, mostly housewives during the above and recorded. The mode of questionnaire administration was face to-face interview with their mothers; relevant information about the child in the family was obtained from the respondent using a pretested structured questionnaire in the local language. If there were more than one child in the family, one of them was chosen randomly. The data on diarrheal episodes were obtained during the interview with a recall period of 2 weeks before, as recommended by WHO [5].

\section{Ethnic value}

A brief introduction was given to the mother of the child or the child care taker regarding the purpose of study and the informed consent was obtained orally. As the first step, the study instrument was used from Water and sanitation project (2009) of Ramachandra University. After the rigorous field visit, discussion with the key informants and an extensive discussion with medical practitioners, Panchayat board officials and from the literature survey [6-8].The questions and variables were modified.

\section{Data analysis}

SPSS 16.0 was used for the statistical analysis of the data cross tabulation, the key influencing factors for the diarrheal occurrence were identified by using binary logistic regression analysis. As the first step chi-square analysis were carried out to filter the variables which are not significant. In second step, the binary logistic regression was carried out for each significant variable to understand the relationship between diarrheal incidences. As a final step, the entire significant variable was computed and the model was run to estimate the risk of ADD for the surveyed households.

\section{Results}

\section{Demographics}

A total of 290 households were visited in 15 wards, 20 households in each ward. The age of the mother ranged between 20 to 40 years, with a mean age of 29 years. Nearly $42 \%$ were in the age group of 26-30 years and 31-35 years were about 35.2\%. Nearly $48 \%$ of female and $56 \%$ of male child belongs to $0-5$ year's age group. The children were in the age of $6-12$ years is $52.3 \%$ female and $42.3 \%$ is male. Male child is comparatively less (33\%) and female child is more $(66 \%)$.

\section{Socio Economic Classification}

The socioeconomic status of the respondents has been categorized as low, middle and high as shown in Table 1. The categorization is based on the range of score obtained by computing the variables like income, educational qualification of mother, father's occupation, dwelling status, floor, type of the house. Out of 290 households, 104 belong to low income group, 155 households come under middle income category and 31 households belongs to high socio-economic category.

\begin{tabular}{|c|c|c|}
\hline Socio Economic Status & Frequency & Percent \\
\hline Low & 104 & 35.8 \\
\hline Middle & 155 & 53.4 \\
\hline High & 31 & 10.6 \\
\hline Total & 290 & 100 \\
\hline
\end{tabular}

Table 1: Socioeconomic Status of the Surveyed Households.

\section{Sources of Water}

In Different Socioeconomic Classification and Diarrheal Prevalence: The lower and middle socioeconomic category mostly depends on community water supply for drinking and domestic purpose, whereas the higher socioeconomic category depends on treated own bore well water for their domestic and drinking purposes.The Table 2 illustrates that the diarrheal prevalence is high between low and middle socio-economic category, who depend on community water supply as the major source for domestic and drinking purposes. During summer season, the supply is intermittent and inadequate leading to storage of water for longer duration. Household storage of water has increased the contamination. Level of contamination depends on various factors such as place of storage, type of container and handling practices [6]. The community water supply in zone 1 is at regular interval because the availability of good quality of water is high in zone 1 when compared to 2 nd and 3 rd zone. In zone 3 the respondents say that the water is supplied once in 7 or 10 days in summer and once in 3 days during winter which leads to storing of water.

\begin{tabular}{|c|c|c|}
\hline \multicolumn{3}{|c|}{ Community Water Supply } \\
\hline Socio Economic Status & With Diarrhea & Without Diarrhea \\
\hline Low & $8(25 \%)$ & $24(75 \%)$ \\
\hline Middle & $9(21.4 .0 \%)$ & $33(78.6 \%)$ \\
\hline High & 0 & $2(100 \%)$ \\
\hline \multicolumn{3}{|c|}{ Own groundwater } \\
\hline Socio Economic Status & With Diarrhea & Without Diarrhea \\
\hline low & $2(18.2 \%)$ & $9(81.8 \%)$ \\
\hline middle & $4(13.8 \%)$ & $25(86.2 \%)$ \\
\hline high & $1(6.2 \%)$ & $15(93.8 \%)$ \\
\hline
\end{tabular}

Table 2: Relation between community water supply as drinking source and diarrheal prevalence. 
Citation: Vaithyanathan L (2017) Risk of Acute Diarrheal Disease in Peri-Urban areas of Chennai, India Countries. J Community Med Public Health: CMPH-105.

Table 3 shows the percentage dependency of groundwater usage of different socioeconomic category and its relationship with diarrheal prevalence. Generally, the long-term settlers depend on the ground water for their domestic purposes. The percentage dependency of ground water is high in southern part of study area where the quality is good. The diarrheal prevalence is comparatively low among the households who depend on ground water. It may be noted that the data shows two children from low socioeconomic status, four from middle and only one from high socioeconomic category has reported diarrhea.

\begin{tabular}{|c|c|c|}
\hline \multicolumn{3}{|c|}{ Purchased water } \\
\hline Socio Economic Status & With Diarrhea & Without Diarrhea \\
\hline Low & $9(14.5 \%)$ & $53(85.5 \%)$ \\
\hline Middle & $7(8.3 \%)$ & $77(91.7 \%)$ \\
\hline High & $1(8.3 \%)$ & $11(91.7 \%)$ \\
\hline \multicolumn{3}{|c|}{$\mathrm{N}=158$} \\
\hline
\end{tabular}

Table 3: Relation between groundwater as drinking source and diarrheal prevalence.

As indicated in Table 4 the purchased water consumers were high in low and middle-income group than in high income. The diarrheal prevalence is also high in low income group $(\mathrm{n}=9)$ and it is considerably low in middle income $(\mathrm{n}=7)$ and drastically low in high income group $(n=1)$. Though the water table is at two feet in zone 3, people have to purchase the water for both domestic and drinking purposes because the ground water is not suitable for any use as the concentration of TDS is more than $20,000 \mathrm{mg} / \mathrm{L}$. The probable cause may be Pallikaranai marsh land is situated near the $3 \mathrm{rd}$ zone and is a contributing factor for the poor quality of water.

\section{Microbial Contamination of Drinking Water}

Microbial Contamination of Drinking Water and its Relation with Diarrhoea: Figure 2 show the contamination of E. coli in drinking water sources and its relation with diarrheal prevalence. E. coli contamination is considerably high in community water and purchased water, which may be due to storage and household handling of water, whereas for the groundwater consumers, there is no need to store the water. The analysis shows clearly that diarrheal prevalence is comparatively high in community water and purchased water consumer than in groundwater consumer. The prevalence of diarrhea being high among the households who depends on purchased water in lower socio-economic category may be due to the improper handling and storage of the water [9].

Table 4 shows the different types of treatment of drinking water before giving to the child of different socioeconomic category. In no treatment category $50 \%$ of low and middle-income group had diarrhea. The prevalence of diarrhea in low and middle socio-economic group is approximately same for the household using boiling and filter technique. Some households reported diarrhea even after boiling the water for 5 minutes the quality of the water was not improved; this may be due to subsequent storage and handling has re-contaminated the water. The analysis strongly shows that the reason for contamination is due to poor storage and handling Most of the high socio-economic group uses commercially available instrumental treatment. The instrumental treatment has significantly reduced the level of contamination. Moreover, the ground water consumers are mostly using the instrumental treatment where the storage of water is not adopted.


Figure 2: Contamination of $E$. coli in Sources of Drinking Water and its Relation with Diarrheal Prevalence

\begin{tabular}{|c|c|c|c|c|c|}
\hline \multicolumn{6}{|c|}{ With Diarrhoea } \\
\hline \multirow[t]{2}{*}{ socio economic status } & \multicolumn{5}{|c|}{ Treatment of water before giving to the child } \\
\hline & No treatment & boil & filter & Instrumental Treatment & others \\
\hline low income & $9(50 \%)$ & $4(22.2 \%)$ & $3(16.7 \%)$ & $2(11 \%)$ & 0 \\
\hline middle income & $10(50 \%)$ & $4(20 \%)$ & $5(25 \%)$ & $1(5 \%)$ & 0 \\
\hline high income & 0 & 0 & $2(66.0 \%)$ & $1(33 \%)$ & 0 \\
\hline \multirow[t]{3}{*}{ I. } & \multicolumn{5}{|c|}{ Treatment of water before giving to the child } \\
\hline & \multicolumn{5}{|c|}{ without diarrhea } \\
\hline & No treatment & boil & filter & Instrumental Treatment & others \\
\hline low income & $51(59.0 \%)$ & $15(17 \%)$ & $15(17 \%)$ & $4(66.7 \%)$ & $1(100.0 \%)$ \\
\hline middle income & $72(53.3 \%)$ & $34(25 \%)$ & $11(8.8 \%)$ & $18(94.7 \%)$ & 0 \\
\hline high income & $6(21 \%)$ & $1(3.6 .0 \%)$ & $3(10.7 \%)$ & $18(54.3 \%)$ & 0 \\
\hline
\end{tabular}

Table 4: Relation between purchased water as drinking source and diarrheal prevalence 
Citation: Vaithyanathan L (2017) Risk of Acute Diarrheal Disease in Peri-Urban areas of Chennai, India Countries. J Community Med Public Health: CMPH-105.

Table 5 summarizes the risk of diarrheal disease by binary logistic analysis. The risk is increased with increase in E.coli count, it increases by 17 times in 31-40 and it increases by 36.5 times in 41-50 E. coli count group in comparison to the constant 0-10 E. coli count group. The analysis clearly establishes that the $E$. coli is the causative agents for the diarrheal prevalence. Higher the income lowers the risk of getting diarrheal diseases. The rate of infection was decreased to 0.535 times in comparison with the constant, i.e., the poor SQI (0-1.6). For the good SQI the risk reduces to 0.48 times in comparison with the constant. It is also observed that having a private toilet reduces the risk to 0.45 times in comparison with household have no facility.

\begin{tabular}{|c|c|c|c|c|}
\hline Variables & Variable Coefficient & OR & p value & S.E. \\
\hline E. coli Count & & & 0 & \\
\hline $20-$ Nov & 1.688 & 5.407 & 0.136 & 1.132 \\
\hline $20-30$ & 1.806 & 6.083 & 0.124 & 1.173 \\
\hline $30-40$ & 2.85 & 17.289 & 0.008 & 1.073 \\
\hline $40-60$ & 3.597 & 36.5 & 0.001 & 1.037 \\
\hline Constant & -4.29 & 0.014 & 0 & 1.007 \\
\hline Toilet facility & & & 0.19 & \\
\hline Private toilet & -0.787 & 0.455 & 0.057 & 0.413 \\
\hline Neighbor's toilet & 0.278 & 1.32 & 0.761 & 0.911 \\
\hline Community toilet & -0.886 & 0.413 & 0.429 & 1.12 \\
\hline Constant (No facility) & -1.194 & 0.303 & 0.001 & 0.361 \\
\hline $\begin{array}{c}\text { Toilet Clean (More than } \\
\text { a week) }\end{array}$ & 0.007 & 1.007 & 0.087 & 0.004 \\
\hline Constant (Once in a week) & -1.945 & 0.143 & 0 & 0.195 \\
\hline
\end{tabular}

Table5: Summaries the risk of diarrheal disease by binary logistic analysis.

\section{Discussion}

The study was designed to assess the risk of ADD and analyzed its link with social and environmental determinants. The study shows that drinking water source is significantly associated with the reduced risk of ADD $26 \%$ of households depend on community water supply which is intermittent in nature. The rate of occurrence of diarrheal cases was high in the households using community water supply $(22.3 \%)$. Diarrheal prevalence is comparatively high in community water sources and purchased water consumer than in groundwater consumers. The prevalence of diarrhea being high among the households who depends on purchased water in lower socio-economic category may be due to the improper handling and storage of the water. Among the three household water treatment methods instrumental treatment (aqua guard, reverse osmosis plant) was effectively reduce the microbial contamination in drinking water than the boiling and filtration method. The key causal link of ADD was identified by using binary logistic regression analysis. The result reveals that the causative factors for diarrheal disease is E. coli contamination in drinking water and less cleaning duration of toilets. General hygiene interventions may play a role in disease prevention, then conducting health campaign, since because it is virtually impossible to isolate the effects of each hygiene measures $[4,8]$.Therefore, some of the researches argued for improving the hygiene behavior [10].

\section{Conclusion}

The study concludes that the ADD diseases in Peri-urban areas can be traced to a variety of independent variables, rather than to a single cause. The results of the household socioeconomic condition survey emphasized for better sanitary conditions and protective water source. A protected water supply, better practices of hygiene behavior can reduce the diarrheal prevalence among young children. Individual household pipe connection instead of street pipe connections will improve the hand wash behavior and cleaning habit of toilets. Promotion of sanitation and personal hygiene will be the cost-effective preventive measures for the diarrheal disease.

\section{Acknowledgements}

The author wishes to acknowledge the Wageningen University, Netherlands and Saki Waters, Hyderabad for providing the research fellowship to carry out the present study. Grateful appreciation is extended to the health offices and the communities of Pallikaranai.

\section{References}

1. WHO (2017) Diarrhoea disease updated fact sheet.

2. Stanly MA, SathiyasekaranBWC,Palani G (2009) 'A Population Based Study of Acute Diarrhoea Among Children Under 5 Years in a Rural Community in South India', Sri Ramachandra Journal of Medicine, $1 \mathrm{H}$ Poor, An Introduction to Signal Detection and Estimation.

3. Green LW (1968) Status inconsistency, reference group theory and preventive health behaviour', Doctoral dissertation, School of Public Health, University of California, Berkeley.

4. E A Aiello \& LE Larson (2002) What is the evidence for a causal link between hygiene and infections?'. The Lancet Infectious Diseases 2: 103-110.

5. Levy K, Nelson KL, Hubbard A,Eisenberg JNS (2008) Following the water: a controlled study of drinking water storage in northern Coastal Ecuador. Environ Health Prospect 116:1533-1540.

6. T Brick, B Primrose, RChandrasekhar, S Roy, J Muliyil, et al. (2004) 'Water Contamination in urban south India. Household storage Practices and their Implications for water safety and enteric infection.Int $\mathrm{J}$ Hyg Environ Health 207: 473-480.

7. Cifuentes E, SuárezL, M Solano, Santos R(2002)Diarrheal diseases in children from a water reclamation site in Mexico City. Environmental Health Perspectives110: A619 - A624.

8. Fewtrall L, KaufmannRB, Kay D, Enanoria W, HallerL,et al. (2005) Water, sanitation and hygiene intervention to preducediarrhoea in Less Developed Countries: A Systematic review and meta-analysis'.Lancet infectious disease 5:42-52. 
Citation: Vaithyanathan L (2017) Risk of Acute Diarrheal Disease in Peri-Urban areas of Chennai, India Countries. J Community Med Public Health: CMPH-105.

9. Yassin MM, Amr SS, Al-Najar HM (2006) Assessment of microbiological water quality and its relation to human health in Gaza Governorate Gaza Strip. Public Health 120:1177-1187.
10. Curtis V, Cairncross S (2003)Effect of washing hands with soap on diarrhea risk in the community, a systematic review. Lancet Infectious Diseases 3: 275-281. 